\title{
Desenvolvimento vegetativo de Mentha campestris Schur e produção de mentol em diferentes espaçamentos de plantio e épocas de colheita
}

\author{
MONTEIRO, R. ${ }^{1 *}$; DESCHAMPS, C. ${ }^{1}$; BIASI, L.A. ${ }^{1}$; BIZZO, H. ${ }^{2}$ \\ ${ }^{1}$ Universidade Federal do Paraná, Setor de Ciências Agrárias, Departamento de Fitotecnia e Fitossanitarismo, Rua \\ dos Funcionários, 1540, CEP:80035-050, Curitiba-Brasil * rodrimont@hotmail.com ²Embrapa Agroindústria de \\ Alimentos, Avenida das Américas, 29501, CEP: 23020-470, Guaratiba-Brasil
}

\begin{abstract}
RESUMO: A produção de óleos essenciais nas plantas aromáticas é influenciada por fatores bióticos e abióticos. A demanda por esses produtos tem aumentado, sendo os óleos essenciais do gênero Mentha de grande interesse nas indústrias farmacêutica, de cosméticos, alimentícia e agrícola, principalmente em função do composto mentol. Esse trabalho teve como objetivo avaliar o efeito de três espaçamentos de plantio $(0,60 \times 0,15 \mathrm{~m} ; 0,60 \times 0,30 \mathrm{~m}$ e 0,60 $\times 0,45 \mathrm{~m})$ e duas épocas de colheita (60 e 90 dias após o plantio) na espécie Mentha campestris Schur. 0 experimento foi conduzido no Centro de Estações Experimentais do Canguiri-UFPR, em PinhaisPR, no período de janeiro a abril de 2008. O delineamento utilizado foi o de blocos ao acaso em esquema de parcelas subdivididas. Houve diferença significativa para todas as variáveis analisadas. As massas secas de folhas, ramos e total foram maiores que na primeira época. Para a biomassa seca de folhas foram observados maiores valores no menor espaçamento de plantio. O rendimento de óleo essencial foi maior na segunda época de colheita e nos espaçamentos maiores. A produtividade do óleo também foi maior na segunda época de colheita, porém no espaçamento mais adensado. Pode-se concluir como recomendação para $M$. campestris Schur o espaçamento $0,60 \times 0,15 \mathrm{~m}$ e colheita aos 90 dias, por terem atingido maior biomassa, rendimento de óleo essencial e produtividade de mentol por hectare.
\end{abstract}

Palavras-chave: menta, espaçamento, colheita, óleo essencial, mentol

\begin{abstract}
Vegetative development of Mentha campestris Schur and menthol production in different row spaces and harvest times. Essential oil production in aromatic plants is influenced by biotic and abiotic factors. The demand for these products has increased, and essential oils from the genus Mentha have been of great interest for pharmaceutical, cosmetic, food and agronomic industries, especially because of the compound menthol. This study aimed to evaluate the effect of three row spaces $(0.60 \times 0.15 \mathrm{~m} ; 0.60 \times 0.30 \mathrm{~m}$ and $0.60 \times 0.45 \mathrm{~m})$ and two harvest times (60 and 90 days after planting) on the species Mentha campestris Schur. The experiment was carried out at Canguiri Experimental Stations-UFPR, in Pinhais, Paraná State, Brazil, between January and April 2008. The experimental design was in randomized blocks in split-plot. There was significant difference for all variables. In the second harvest time, leaf, branch and total dry yields were higher than those in the first time. For leaf dry mass, the highest values were observed in the narrowest space. Essential oil yield was higher in the second harvest and in wider rows. Essential oil productivity was also higher in the second harvest time, but in the narrowest row. The space $0.60 \times 0.15 \mathrm{~m}$ and harvest at 90 days can be recommended due to their higher biomass, essential oil yield and menthol productivity per hectare.
\end{abstract}

Key words: mint, spacing, harvest, essential oil, menthol

\section{INTRODUÇÃO}

A espécie Mentha campestris pertence ao gênero Mentha, que compreende plantas distribuídas em todo o mundo e que têm como centro de origem a Europa meridional e a região do Mediterrâneo. São plantas perenes, com folhas opostas, pecioladas e pubescentes, com flores de coloração lilás ou branca, reunidas em espigas nas axilas das folhas (Mattos, 2000).

Recebido para publicação em 17/08/2009

Aceito para publicação em 20/06/2011

Rev. Bras. PI. Med., Botucatu, v.13, n.4, p.401-407, 2011. 
Algumas espécies de menta são cultivadas de maneira intensiva em diversos países, devido ao interesse econômico na produção do monoterpeno mentol (Khanuja et al., 2000). Em 2002, o quilograma do óleo essencial de menta estava cotado em US\$ 54 (Paulus et al., 2007). Além do mentol, outros constituintes ajudam a definir a qualidade do óleo, como a pulegona, mentona e carvona (Franzios et al., 1997). Rao (1999) cita para Mentha arvensis var. piperascens teor aproximado de óleo essencial de $1,5 \%$ e até $70 \%$ de mentol.

Espaçamentos de plantio alteram a capacidade de interceptação de luz, o que pode resultar na diminuição da capacidade fotossintética das plantas e, conseqüentemente, seu crescimento (Taiz \& Zeiger, 2004). Além disso, a densidade de plantas no campo pode contribuir positiva ou negativamente para a competição entre a cultura e plantas invasoras por recursos como água, radiação e nutrientes.

A época de colheita também influencia o rendimento e composição do óleo essencial de plantas aromáticas. Diversos trabalhos relatam que colheitas no período de pleno florescimento são recomendadas por apresentarem maiores concentrações de mentol (Randhawa \& Satinder, 1996; Aflatuni, 2005; Rohloff et al., 2005). A espécie $M$. campestris Schur., conforme resultados prévios, apresenta alto teor de mentol no óleo essencial.

Dada a importância desse composto e a demanda crescente pelo cultivo de espécies de menta, investigou-se neste trabalho o efeito de diferentes espaçamentos de plantio e épocas de colheita no desenvolvimento de $M$. campestris Schur., no desenvolvimento vegetativo, bem como no teor e produtividade de mentol.

\section{MATERIAL E MÉTODO}

O experimento foi conduzido de janeiro a abril de 2008, no Centro de Estações Experimentais do Canguiri (CEEx) - UFPR no município de Pinhais, Região Metropolitana de Curitiba, localizado à 2523.258' latitude Sul, 4907.713' longitude Oeste, com 919 m de altitude. A região apresenta clima subtropical úmido meso-térmico, sendo que no decorrer do experimento o índice pluviométrico médio mensal foi de 148,75 milímetros com temperaturas médias de $25,1^{\circ} \mathrm{C}$, mínima de $9,0^{\circ} \mathrm{C}$ e máxima de $30,6^{\circ} \mathrm{C}$, registrados pelo Sistema Meteorológico do Paraná (SIMEPAR).

O solo da área experimental é cambissolo háplico (EMBRAPA, 1999), cujos resultados da análise química encontram-se na Tabela 1. A amostragem do solo foi realizada na profundidade de 0-20 cm, seguindo metodologia de Pavan et al. (1992).

TABELA 1. Análise de solo da área experimental, coletado na profundidade de 0-20 cm. Pinhais, PR, 2008.

\begin{tabular}{|c|c|c|c|c|c|c|c|c|c|c|}
\hline $\mathrm{pH}$ & $\mathrm{Al}^{3+}$ & $\mathrm{Ca}^{2+}$ & $\mathrm{Mg}^{2+}$ & $\mathrm{K}^{+}$ & SB & $\mathrm{T}$ & $\mathrm{P}$ & C & V & Argila \\
\hline SMP & \multicolumn{6}{|c|}{$\mathrm{cmol}_{\mathrm{c}} \mathrm{dm}^{-3}$} & $\mathrm{mg} \mathrm{dm}^{-3}$ & $\mathrm{G} \mathrm{dm}^{-3}$ & \multicolumn{2}{|c|}{$\%$} \\
\hline 6,30 & 0,00 & 7,70 & 3,30 & 1,15 & 12,15 & 16,15 & 158,00 & 32,9 & 75 & 40 \\
\hline
\end{tabular}

A correção da acidez e da fertilidade da área foi feita com base na recomendação de adubação e calagem da Comissão de Química e Fertilidade do Solo do RS e SC (2004) para a cultura da menta. Foram aplicados $10 \mathrm{~kg} \mathrm{ha}^{-1} \mathrm{de} \mathrm{N}, 40 \mathrm{~kg} \mathrm{ha}^{-1}$ de $\mathrm{P}_{2} \mathrm{O}_{5}$, $30 \mathrm{~kg} \mathrm{ha}^{-1}$ de $\mathrm{K}_{2} \mathrm{O}$ e $1,8 \mathrm{t}^{-1}$ de calcário tipo Filler (PRNT 100\%), para corrigir o pH SMP para 6,0. A adubação de cobertura foi realizada com $10 \mathrm{~kg} \mathrm{ha}^{-1}$ de $\mathrm{N}$ aos 30 dias após o plantio. Antes do plantio os fertilizantes (uréia, super triplo e cloreto de potássio) e o calcário (tipo filler) foram incorporados por operação de gradagem.

As mudas da espécie Mentha campestris foram fornecidas pela Embrapa/Cenargen, Brasília, DF, sendo multiplicadas por estaquia herbácea. As estacas, de $10 \mathrm{~cm}$ e com meio par de folhas, foram obtidas a partir de ramos das plantas-mães, cultivadas em vaso em condições de casa-devegetação. Após o preparo, as estacas permaneceram em bandejas de isopor de 200 células, com substrato Plantmax ${ }^{\circledR}$ hortaliças, sob irrigação por aspersão diária até o enraizamento (aproximadamente 40 dias).

O delineamento experimental foi em blocos ao acaso, em esquema de parcelas subdivididas, com 6 tratamentos avaliando o efeito de três espaçamentos $(0,60 \times 0,15 \mathrm{~m} ; 0,60 \times 0,30 \mathrm{~m} ; 0,60 \times$ $0,45 \mathrm{~m}$ ) nas parcelas e duas épocas de colheita (60 e 90 dias após o plantio) nas subparcelas, com 4 repetições. A área das parcelas era de $6,5 \mathrm{~m}^{2}$, com 4 plantas na parcela útil, sendo diferentes parcelas úteis para avaliar cada época de colheita.

Durante os três meses de cultivo as plantas foram irrigadas em dias alternados por aspersão; sendo realizadas capinas quinzenais nas parcelas. Não houve incidência de pragas e doenças durante o ciclo de cultivo. As colheitas na área experimental foram realizadas no final do verão (60 dias após o plantio) e no outono (90 dias após o plantio). Os cortes foram realizados manualmente, com tesoura de poda, a 10

Rev. Bras. PI. Med., Botucatu, v.13, n.4, p.401-407, 2011. 
TABELA 2. Tratamentos testados no experimento de M. campestris, em Pinhais, PR, 2008.

\begin{tabular}{ccc}
\hline Tratamento & $\begin{array}{c}\text { Espaçamento (entre plantas } \mathrm{x} \\
\text { entrelinhas) em m }\end{array}$ & $\begin{array}{c}\text { Épo ca de colheita (dias após } \\
\text { o plantio) }\end{array}$ \\
\hline T1 & $0,15 \times 0,60$ & 60 \\
T2 & $0,15 \times 0,60$ & 90 \\
T3 & $0,30 \times 0,60$ & 60 \\
T4 & $0,30 \times 0,60$ & 90 \\
T5 & $0,45 \times 0,60$ & 60 \\
T6 & $0,45 \times 0,60$ & 90 \\
\hline
\end{tabular}

cm do solo, acondicionando separadamente a parte aérea dos estolões.

Para avaliar o desenvolvimento vegetativo, determinou-se a massa seca de ramos, folhas, número de estolões, comprimento do ramo principal e o índice de área foliar (IAF) pela estimativa da área foliar pelo método do disco (Fernandes, 2000). Para a extração do óleo essencial foram utilizadas amostras de $100 \mathrm{~g}$ de massa fresca de folhas, submetidas à hidrodestilação em aparelho graduado de Clevenger durante 2 horas. $O$ teor de óleo essencial foi corrigido para base seca após secagem de amostras foliares a $65^{\circ} \mathrm{C}$ em estufa com ventilação forçada até massa constante.

A análise dos constituintes do óleo essencial foi realizada por meio de cromatografia a gás acoplada à espectrometria de massas (CG/EM), pela EMBRAPA Agroindústria de Alimentos - RJ. Utilizou-se cromatógrafo a gás da marca Varian, modelo CP 3800 , com detector FID (CG-FID); coluna capilar HP 5 com $0,32 \mathrm{~mm}$ de diâmetro interno, $30 \mathrm{~m}$ de comprimento e $0,25 \mu \mathrm{m}$ de filme líquido. As condições de análise foram as seguintes: a) temperatura do injetor: $250^{\circ} \mathrm{C}$, split 1:20; b) quantidade de amostra injetada: 1,0 $\mu \mathrm{L}$; ) gás de arraste: hélio a 1,0 $\mathrm{mL} \mathrm{min}^{-1}$ na temperatura de $40^{\circ} \mathrm{C}$; d) temperatura do detector FID: $250^{\circ} \mathrm{C}$; e) programação da temperatura do forno: inicial $60^{\circ} \mathrm{C}$, elevação da temperatura a $240^{\circ} \mathrm{C}$ na razão de $3^{\circ} \mathrm{C}$ por minuto; f) tempo total da corrida: 50 minutos. A identificação dos constituintes químicos foi realizada comparando-se à biblioteca da Nist 98 (Varian Inc.).

As análises de variância (ANOVA) foram realizadas utilizando o programa ASSISTAT versão 7.4 beta (Silva \& Azevedo, 2006). As variâncias dos tratamentos foram testadas quanto à sua homogeneidade pelo teste de Bartlett e as médias dos tratamentos comparadas pelo teste de Tukey ao nível de $5 \%$ de probabilidade.

\section{RESULTADO E DISCUSSÃO}

\section{Desenvolvimento vegetativo}

Os resultados dos efeitos dos tratamentos de épocas de colheita sobre o acúmulo de massa seca de ramos, de folhas, massa seca total e razão massa seca de folhas por massa seca total de Mentha campestris encontram-se na Tabela 3.

A massa seca de folhas e ramos foi superior na 2a época de colheita, devido ao maior período de cultivo que permitiu às plantas maior acúmulo massa seca total. Resultados semelhantes foram obtidos por Inneco et al. (2003) e Aflatuni (2005) em espécies de Mentha colhidas em diferentes épocas.

Em Mentha arvensis, Ram \& Kumar (1997) citam maior acúmulo de massa seca $\left(6,6 \mathrm{t} \mathrm{ha}^{-1}\right) \mathrm{em}$ plantas com maior tempo de cultivo (120 dias). A razão da massa seca de folhas/massa seca total, maior na 1a colheita, significa que por ocasião dos 60 dias após o plantio havia mais folhas que ramos, assim como Czepak (1995) obteve em Mentha arvensis. Quanto ao comprimento do ramo principal não houve interação entre os fatores (Tabela 4).

Entre os espaçamentos, o que apresentou comprimento superior foi o de $0,15 \times 0,60 \mathrm{~m}$, o que

TABELA 3. Massa seca de ramos, folhas e massa seca total $(\mathrm{g})$ e razão massa seca de folhas/massa seca total de M. campestris em diferentes épocas de colheita. Pinhais, PR, 2008.

\begin{tabular}{ccccc}
\hline Época de col heita & MS Folhas & MS Ramos & MS Total & $\begin{array}{c}\text { MS Folhas/ } \\
\text { MS Total }\end{array}$ \\
\hline 60 dias & $22,75 \mathrm{~b}$ & $8,63 \mathrm{~b}$ & $31,38 \mathrm{~b}$ & $0,70 \mathrm{a}$ \\
90 dias & $35,47 \mathrm{a}$ & $20,71 \mathrm{a}$ & $56,18 \mathrm{a}$ & $0,61 \mathrm{~b}$ \\
\hline Coeficiente de Variação (\%) & 24,76 & 32,38 & 27,50 & 4,29 \\
\hline
\end{tabular}

Médias seguidas pela mesma letra nas colunas não diferem estatisticamente entre si pelo teste de Tukey ao nível de 5\%.

Rev. Bras. PI. Med., Botucatu, v.13, n.4, p.401-407, 2011. 
pode estar associado à competição por luz observada em populações com maior densidade de plantio. Rao (2002), avaliando espaçamentos de plantio em espécies do gênero Pelargonium, obteve plantas com média de $52,5 \mathrm{~cm}$ no espaçamento de $60 \mathrm{~cm}$, quando comparadas ao espaçamento entre plantas de 120 $\mathrm{cm}$, que atingiram, na média, $44,6 \mathrm{~cm}$.

TABELA 4. Comprimento do ramo principal $(\mathrm{cm})$ de M. campestris sob diferentes espaçamentos e épocas de colheita. Pinhais, PR, 2008.

\begin{tabular}{|c|c|c|c|}
\hline \multirow{2}{*}{$\begin{array}{c}\text { Espaçamento } \\
(\mathrm{m})\end{array}$} & \multicolumn{2}{|c|}{ Época de colheita } & \multirow{2}{*}{ Média } \\
\hline & 60 dias & 90 dias & \\
\hline $0,15 \times 0,60$ & $32,81 \mathrm{~ns}$ & $43,16 \mathrm{~ns}$ & $37,98 \mathrm{a}$ \\
\hline $0,30 \times 0,60$ & $26,12 \mathrm{~ns}$ & $37,20 \mathrm{~ns}$ & $31,66 \mathrm{~b}$ \\
\hline $0,45 \times 0,60$ & $28,34 \mathrm{~ns}$ & $32,88 \mathrm{~ns}$ & $30,61 \mathrm{~b}$ \\
\hline Média & $29,09 \mathrm{~b}$ & $37,74 \mathrm{a}$ & \\
\hline
\end{tabular}

Médias seguidas pela mesma letra não diferem estatisticamente entre si pelo teste de Tukey ao nível de $5 \%$.

O comprimento do ramo principal também foi superior na segunda época de colheita. Assim como para as variáveis de acúmulo de massa, o maior período de cultivo favoreceu o maior comprimento de ramos.

Não houve interação entre os espaçamentos e as épocas de colheita para o acúmulo de biomassa seca de folhas, sendo afetado apenas pelo espaçamento. Plantios com menores densidades (espaçamento 0,45 x 0,60 m) resultaram em menor produção de biomassa por área, no entanto, não houve diferença quando foi adotado o espaçamento de 15 ou $30 \mathrm{~cm}$ entre plantas na linha. Na Tabela 5 estão os dados das médias das épocas de colheita para cada espaçamento. Em experimento com plantas do gênero Pelargonium, em espaçamentos entre linhas de $60 \mathrm{e}$ $75 \mathrm{~cm}$, Rao (2002) obteve maiores valores de biomassa, ao comparar com espaçamentos de $90 \mathrm{e}$ $120 \mathrm{~cm}$. Aflatuni (2005) também obteve maiores valores de biomassa de folhas em plantios mais adensados.

Para o número de estolões (Tabela 6) houve interação significativa entre os fatores espaçamento e época de colheita. Os resultados demonstram que na primeira época de colheita, maior número de estolões foi obtido no espaçamento $0,30 \times 0,60 \mathrm{~m}$. $\mathrm{Na}$ colheita realizada aos 90 dias, porém, a densidade de plantas não afetou o número de estolões.

O número inferior de estolões em plantio mais adensado pode estar relacionado com as condições de maior competição entre plantas, quando o crescimento vertical é favorecido em detrimento do crescimento de estolões. O menor número observado na segunda época de colheita coincide com o descrito
TABELA 5. Produtividade de biomassa foliar $\left(\mathrm{kg} \mathrm{ha}^{-1}\right)$ de $M$. campestris sob diferentes espaçamentos de plantio. Pinhais, PR, 2008.

\begin{tabular}{cc}
\hline $\begin{array}{c}\text { Espaçamento } \\
(\mathrm{m})\end{array}$ & $\begin{array}{c}\text { Biomassa de folhas } \\
\left(\mathrm{kg} \mathrm{ha}^{-1}\right)\end{array}$ \\
\hline $0,15 \times 0,60$ & $2733,87 \mathrm{a}$ \\
$0,30 \times 0,60$ & $2443,55 \mathrm{a}$ \\
$0,45 \times 0,60$ & $1821,18 \mathrm{~b}$ \\
\hline
\end{tabular}

Médias seguidas pela mesma letra não diferem estatisticamente entre si pelo teste de Tukey ao nível de $5 \%$.

TABELA 6. Número de estolões de $M$. campestris sob diferentes espaçamentos de plantio e épocas de colheita. Pinhais, PR, 2008.

\begin{tabular}{ccc}
\hline \multirow{2}{*}{$\begin{array}{c}\text { Espaçamento } \\
(\mathrm{m})\end{array}$} & \multicolumn{2}{c}{ Época de colheita } \\
\cline { 2 - 3 } & 60 dias & 90 dias \\
\hline $0,15 \times 0,60$ & $2,37 \mathrm{Ac}$ & $2,25 \mathrm{Aa}$ \\
$0,30 \times 0,60$ & $8,33 \mathrm{Aa}$ & $1,58 \mathrm{Ba}$ \\
$0,45 \times 0,60$ & $5,16 \mathrm{Ab}$ & $2,41 \mathrm{Ba}$ \\
\hline
\end{tabular}

Médias seguidas pela mesma letra minúscula nas colunas e maiúscula nas linhas não diferem estatisticamente entre si, pelo teste de Tukey ao nível de 5\%.

por Aflatuni (2005), que cita aumento de massa, mas diminuição no número de estolões. Esta variável é de grande importância na cultura da menta considerando que os estolões são utilizados na propagação vegetativa, podendo representar diminuição nos custos de produção e de mão de obra no preparo de mudas.

Conforme a Tabela 7, todos os espaçamentos apresentaram maior IAF, índice adimensional, na segunda colheita, cujos plantios com 15 ou $30 \mathrm{~cm}$ entre plantas resultaram em maiores médias. Portanto, o aumento de área foliar nestas condições, devido ao número de folhas e/ou expansão foliar, pode ser responsável pelo maior acúmulo de massa seca (Tabela 3). Em manjericão, Sifola \& Barbieri (2006) atribuíram maiores valores de IAF ao maior número de folhas por planta, e não à expansão foliar individual. No presente trabalho não foi quantificado o número de folhas.

\section{Teor e produtividade de óleo essencial e de mentol}

Houve interação significativa entre os fatores para o teor de óleo essencial. Embora na primeira época de colheita não tenha sido observada diferença entre os espaçamentos, na segunda época menores teores de óleo essencial ocorreram em plantios mais adensados. Utilizando-se espaçamentos de 0,30 ou $0,45 \times 0,60 \mathrm{~m}$, os teores entre as épocas de colheita 
TABELA 7. Índice de área foliar (IAF) de M. campestris sob diferentes espaçamentos de plantio e épocas de colheita. Pinhais, PR, 2008.

\begin{tabular}{clc}
\hline Espaçamento & \multicolumn{2}{c}{ Época de colheita } \\
\cline { 2 - 3 }$(\mathrm{m})$ & $60 \mathrm{dias}$ & 90 dias \\
\hline $0,15 \times 0,60$ & $4,49 \mathrm{Ba}$ & $5,81 \mathrm{Aa}$ \\
$0,30 \times 0,60$ & $2,23 \mathrm{Bb}$ & $5,45 \mathrm{Aa}$ \\
$0,45 \times 0,60$ & $1,56 \mathrm{Bb}$ & $4,20 \mathrm{Ab}$ \\
\hline
\end{tabular}

Médias seguidas pela mesma letra minúscula nas colunas e maiúscula nas linhas não diferem estatisticamente entre si, pelo teste de Tukey ao nível de $5 \%$.

não diferiram (Tabela 8). Estes resultados demonstram que a radiação afeta o teor de óleo essencial em $M$. campestris. Esse efeito também foi observado por Castro (2007) com espécies de Mentha, que apresentaram maiores teores de óleo essencial, mentol e mentona em níveis mais intensos de radiação. Também avaliando diferentes espécies de Mentha, Deschamps et al. (2008) concluíram que a diminuição do teor de óleo essencial por ocasião do inverno estava relacionado à diminuição da temperatura, umidade e da radiação. Nesse experimento, na primeira época de colheita a competição por radiação ainda não era suficiente para causar redução nos teores de óleo essencial. $\mathrm{Na}$ segunda época de colheita, quando as plantas apresentavam desenvolvimento superior, o plantio mais adensado, e conseqüente maior redução de radiação disponível no perfil das plantas, afetou o teor de óleo.

Resultados semelhantes foram observados em diferentes espécies de Mentha por Ozel \& Ozguven (2002), Castro (2007) e também por Aflatuni (2005). Ram \& Kumar (1997) em M. arvensis atribuíram à senescência das folhas inferiores a queda na razão folha/ramos e no teor de óleo essencial em plantas sob adubação nitrogenada e, logo, maior crescimento e sombreamento. Pelo fato das folhas inferiores (maiores em tamanho e com maior capacidade de

TABELA 8. Teor de óleo essencial $\left(\mu \mathrm{L} \mathrm{MS}^{-1}\right)$ de $M$. campestris sob diferentes espaçamentos de plantio e épocas de colheita. Pinhais, PR, 2008.

\begin{tabular}{|c|c|c|}
\hline \multirow{2}{*}{$\begin{array}{c}\text { Espaçamento } \\
(\mathrm{m})\end{array}$} & \multicolumn{2}{|c|}{ Época de colheita } \\
\hline & 60 dias & 90 dias \\
\hline $0,15 \times 0,60$ & $55,38 \mathrm{Aa}$ & $35,96 \mathrm{Bb}$ \\
\hline $0,30 \times 0,60$ & $49,80 \mathrm{Aa}$ & $47,21 \mathrm{Aa}$ \\
\hline $0,45 \times 0,60$ & $47,72 \mathrm{Aa}$ & $50,23 \mathrm{Aa}$ \\
\hline
\end{tabular}

armazenamento de óleo essencial) sofrerem o mesmo efeito em plantio mais adensado, os resultados observados no espaçamento $0,15 \times 0,60 \mathrm{~m}$ poderiam estar associados à senescência foliar.

A produtividade do óleo essencial (Tabela 9) foi afetada pelos fatores isoladamente, quando 0 menor espaçamento $(0,15 \times 0,60 \mathrm{~m})$ resultou em produtividade de óleo essencial superior, devido a maior produção de biomassa foliar nestas condições. Trabalhos anteriores com diferentes espécies de Menthatêm demonstrado que a produção de biomassa foliar é o fator determinante na produtividade de óleo essencial, e não as variações dos teores de óleo essencial (Ram \& Kumar, 1998; Rao, 2002; Aflatuni, 2005).

TABELA 9. Produtividade de óleo essencial $\left(\mathrm{Lha}^{-1}\right)$ de $M$. campestris sob diferentes espaçamentos e épocas de colheita. Pinhais, PR, 2008.

\begin{tabular}{cccc}
\hline \multirow{2}{*}{$\begin{array}{c}\text { Espaçamento } \\
(\mathrm{m})\end{array}$} & \multicolumn{2}{c}{ Época de colheita } & \\
\cline { 2 - 3 } & 60 dias & 90 dias & Média \\
\hline $0,15 \times 0,60$ & $182,58 \mathrm{~ns}$ & $216,37 \mathrm{~ns}$ & $199,48 \mathrm{a}$ \\
$0,30 \times 0,60$ & $87,67 \mathrm{~ns}$ & $149,38 \mathrm{~ns}$ & $118,52 \mathrm{~b}$ \\
$0,45 \times 0,60$ & $63,40 \mathrm{~ns}$ & $117,82 \mathrm{~ns}$ & $90,61 \mathrm{~b}$ \\
\hline Média & $111,22 \mathrm{~b}$ & $161,19 \mathrm{a}$ & \\
\hline
\end{tabular}

Médias seguidas pela mesma letra não diferem estatisticamente entre si pelo teste de Tukey ao nível de $5 \%$.

De forma semelhante, na segunda época de colheita foram obtidas maiores produtividades, compensando o menor teor de óleo essencial de plantio mais adensado. Embora relatado anteriormente que para espécies de menta o período de maior produtividade de óleo essencial ocorre no período do florescimento (Kofidis \& Bosabalidis, 2004; Aflatuni, 2005; Rohloff et al., 2005), no presente trabalho não foi observada esta correlação, já que na primeira colheita as plantas já estavam em florescimento e a produtividade de óleo essencial foi superior na segunda colheita. Em M. arvensisresultados semelhantes foram obtidos por Czepak (1995) e, portanto, também para $M$. campestris a produtividade de óleo não é diretamente afetada pelo estágio fenológico, e sim com o acúmulo de massa foliar, que é crescente mesmo após o início do florescimento.

Para os componentes majoritários do óleo essencial, o único que apresentou interação significativa entre os fatores avaliados foi o mentol (Tabela 10).

Mesmo havendo tendência de aumento da concentração de mentol por ocasião da segunda colheita, os valores indicam que não há diferença nos 
teores entre os espaçamentos e as épocas de colheita. Resultados semelhantes obtiveram Aflatuni (2005) e Rohloff et al. (2005). Há evidências de que o teor de mentol aumenta com o tempo de cultivo até certo período após o florescimento, como observaram Randhawa \& Satinder (1996); Marcum \& Hanson (2006) e Scavroni et al. (2005). Além disso, tem sido observado quanto à idade das folhas, que o teor de mentol é maior em folhas mais velhas (Maffei et al., 1989; Turner et al., 2000), o que pode explicar os resultados observados. Pelo fato da biossíntese do mentol ser derivada do metabolismo primário da planta, uma vez que os monoterpenos são sintetizados a partir da incorporação de $\mathrm{CO}_{2}$, a qual depende da taxa de fotossíntese (Gershenzon et al., 2000), pode haver prioridade ao crescimento e desenvolvimento da planta em relação à produção de óleo essencial (metabolismo secundário), principalmente durante o início do ciclo. Croteau et al. (2005) afirmam que a formação dos tricomas glandulares peltados ocorre até o momento em que a expansão foliar cessa, porém, a biossíntese dos compostos do óleo essencial é temporalmente diferenciada. O mentol, como já citado, tem a tendência de aumentar a concentração no decorrer do ciclo de cultivo em função da enzima mentona-redutase, que só se expressa próximo ao florescimento, dada a necessidade de concentração de substrato e outros possíveis co-fatores (Croteau et al., 2005).

A produtividade do constituinte de maior valor comercial no óleo essencial, o mentol, não foi afetada pela interação dos fatores. Conforme resultados da Tabela 11, maiores produtividades foram obtidas no plantio mais adensado e quando a colheita foi realizada aos 90 dias, resultados também decorrentes do maior produtividade de óleo essencial, já que os teores de mentol não foram afetados pelos fatores espaçamento e época de colheita.

Tendo em vista que a produtividade de mentol é função dos valores de produtividade de óleo ( $\left(\mathrm{ha}^{-1}\right)$ e de porcentagem de mentol, explicam-se os resultados observados, já que para ambas variáveis os maiores valores foram observados no menor

TABELA 10. Porcentagem de mentol no óleo essencial de $M$. campestris sob diferentes espaçamentos de plantio e épocas de colheita. Pinhais, PR, 2008.

\begin{tabular}{ccc}
\hline Espaçamento & \multicolumn{2}{c}{ Época de colheita } \\
\cline { 2 - 3 }$(\mathrm{m})$ & 60 dias & 90 dias \\
\hline $0,15 \times 0,60$ & $82,78 \mathrm{Ab}$ & $84,63 \mathrm{Aab}$ \\
$0,30 \times 0,60$ & $83,29 \mathrm{Ab}$ & $85,59 \mathrm{Aa}$ \\
$0,45 \times 0,60$ & $83,61 \mathrm{Aa}$ & $84,01 \mathrm{Ab}$ \\
\hline
\end{tabular}

Médias seguidas pela mesma letra minúscula nas colunas e maiúscula nas linhas não diferem estatisticamente entre si pelo teste de Tukey ao nível de 5\%.
TABELA 11. Produtividade de mentol ( $\left.L \mathrm{ha}^{-1}\right)$ de $M$. campestris sob diferentes espaçamentos e épocas de colheita. Pinhais, PR, 2008.

\begin{tabular}{cccc}
\hline \multirow{2}{*}{\begin{tabular}{c} 
Espaçamento $(\mathrm{m})$ \\
\cline { 2 - 3 }
\end{tabular}} & \multicolumn{2}{c}{ Época de colheita } & \\
& 60 dias & 90 dias & \\
\hline $0,15 \times 0,60$ & $151,15 \mathrm{~ns}$ & $183,57 \mathrm{~ns}$ & $167,36 \mathrm{a}$ \\
$0,30 \times 0,60$ & $73,10 \mathrm{~ns}$ & $126,74 \mathrm{~ns}$ & $99,92 \mathrm{~b}$ \\
$0,45 \times 0,60$ & $52,97 \mathrm{~ns}$ & $99,94 \mathrm{~ns}$ & $76,45 \mathrm{~b}$ \\
\hline Média & $92,41 \mathrm{~b}$ & $136,75 \mathrm{a}$ & \\
\hline
\end{tabular}

Médias seguidas pela mesma letra não diferem estatisticamente entre si pelo teste de Tukey ao nível de 5\%.

espaçamento e na segunda época de colheita.

Dessa forma, a densidade de plantio e a época de colheita afetam o desenvolvimento vegetativo e o teor de óleo essencial de Mentha campestris.

Embora o teor de óleo essencial seja inferior em colheita realizada aos 90 dias, em plantios mais adensados, maiores produtividades de óleo essencial e de mentol são obtidos nestas condições, devido ao maior acúmulo de biomassa foliar.

Para a região e épocas do ano estudadas, as melhores condições de desenvolvimento vegetativo e produção de mentol em Mentha campestris são o espaçamento $0,15 \times 0,60 \mathrm{~cm}$ e colheita aos 90 dias após o plantio, tendo em vista as produtividades de óleo essencial e mentol.

\section{AGRADECIMENTO}

À EMBRAPA/CENARGEN - Centro Nacional de Pesquisa de Recursos Genéticos e Biotecnologia, pelo fornecimento do material vegetal.

\section{REFERÊNCIA}

AFLATUNI, A. The yield and essential content of mint (Mentha ssp) in northern Ostrobothnia. 2005. 50p. Dissertação (Mestrado) - Departamento de Biologia, Universidade de Oulu, Oulu.

CASTRO, L.W.P. Desenvolvimento de Mentha aquatica e Mentha x piperita, rendimento e qualidade do óleo essencial em resposta a níveis de radiação e adubação nitrogenada. 2007. 52p. Dissertação (Mestrado - Área de Concentração em Produção Vegetal) - Departamento de Fitotecnia e Fitossanitarismo, Universidade Federal do Paraná, Curitiba.

COMISSÃO DE QUÍMICA E FERTILIDADE DO SOLO. Manual de Adubação e calagem para os Estados do Rio Grande do Sul e Santa Catarina. Porto Alegre: SBCS Núcleo Regional Sul, 2004. 400p.

CROTEAU, R. et al. (-)- Menthol biosynthesis and molecular genetics. Naturwissenschaften, v.92, n.12, p. 562-77, 2005. 
CZEPAK, M.P. Produção de óleo bruto e mentol cristalizável em oito frequências de colheita de Menta (Mentha arvensis L.). In: MING, L.C. et al. (Eds.). Plantas medicinais, aromáticas e condimentares: avanços na pesquisa agronômica. Botucatu: UNESP, 1995. p.53-80. DESCHAMPS, C. et al. Avaliação sazonal do rendimento de óleo essencial em espécies de menta. Ciência e Agrotecnologia, v.32, n.3, p.725-30, 2008.

EMPRESABRASILEIRA DE PESQUISAAGROPECUÁRIA (EMBRAPA). Sistema Brasileiro de Classificação de solos. Brasília: Embrapa Produção de Informação, 1999. 412p.

FERNANDES, P.D. Análise de crescimento e desenvolvimento vegetal. Campina Grande: UFPB, Departamento de Engenharia Agrícola, 2000. 22p.

FRANZIOS, G. et al. Insecticidal and genotoxic activities of mint essential oils. Journal of Agricultural Food and Chemistry, v.45, n.7, p.2690-4, 1997.

GERSHERZON, J.; McCONKEY, M.E.; CROTEAU, R.B. Regulation of monoterpene accumulation in leaves of peppermint. Plant Physiology, v.122, n.1, p.205-13, 2000. INNECO, R. et al. Espaçamento, época e número de colheitas em hortelã rasteira (Mentha $\mathrm{x}$ villosa Huds). Revista Ciência Agronômica, v.34, n.2, p.247-51, 2003. KHANUJA, S.P.S. et al. Assessment of genetic relationships in Mentha species. Euphytica, v.111, n.2, p.121-5, 2000.

KOFIDIS, G.; BOSABALIDIS, A. Seasonal variation of essential oils in a linalool-rich chemotype of Mentha spicata grown wild in Greece. Journal of Essential Oil Research, v.16, p.469-72, 2004.

MAFFEI, M.; CHIALVA, F.; SACCO, T. Glandular trichomes and essential oils in developing peppermint leaves. New Phytologist Trust, v.111, n.104, p.707-16, 1989.

MARCUM, D.B.; HANSON, B.R. Effect of irrigation and harvest timing on peppermint oil yield in California. Agricultural Water Management, v.82, n.2, p.118-28, 2006.

MATTOS, S.H. Estudos fitotécnicos da Mentha arvensis L. var. Holmes como produtora de mentol no Ceará. 2000. 97p. Tese (Doutorado - Área de Concentração em Fitotecnia) - Centro de Ciências Agrárias, Universidade Federal do Ceará, Fortaleza.

OZEL, A.; OZGUVEN, M. Effect of different planting times on essential oil components of different mint (Mentha spp.) varieties. Turkish Journal of Agriculture and Forestry, v.26, n.5, p.289-94, 2002.

PAULUS, D. et al. Teor e qualidade do óleo essencial de menta (Mentha arvensis L.) produzida sob cultivo hidropônico e em solo. Revista Brasileira de Plantas Medicinais, v.9, n.2, p.80-7, 2007.

PAVAN, M.A. et al. Manual de análise química de solo e controle de qualidade. Londrina: IAPAR, 1992. 40p. (IAPAR, Circular 76).

RAM, M.; KUMAR, S. Yield improvement in the regenerated and transplanted mint Mentha arvensis by recycling the organic wastes and manures. Bioresource Technology, v.59, n.2, p.141-9, 1997.

RANDHAWA, G.; SATINDER, K. Optimization of harvesting time and row spacing for the quality oil in cornmint (Mentha arvensis L.) varieties. Acta Horticulturae, v.1, n.426, p.615-22, 1996.

RAO, B.R.R. Biomass and essential oil yields of cornmint (Mentha arvensis L. f. piperascens Malinvaud ex Holmes) planted in different months in semi-arid tropical climate. Indutrial Crops and Products, v.10, n.2, p.107-13, 1999. RAO, B.R.R. Biomass yield, essential oil yield and essential oil composition of rose-scented geranium (Pelargonium species) as influenced by row spacings and intercropping with cornmint (Mentha arvensis $L$. $f$. piperascens Malinv. Ex Holmes). Industrial Crops and Products, v.16, n.2, p.133-44, 2002.

ROHLOFF, J. et al. Effect of harvest time and drying method on biomass production, essential oil yield and quality of peppermint (Mentha x piperita L.). Journal of Agricultural and Food Chemistry, v.53, n.10, p.4143-8, 2005.

SCAVRONI, J. et al. Yield and composition of the essential oil of Mentha piperita L. (Lamiaceae) grown with biosolid. Brazilian Journal of Plant Physiology, v.17, n.4, p.34552, 2005.

SIFOLA, M.I.; BARBIERI, G. Growth, yield and essential oil content of three cultivars of basil grown under different levels of nitrogen in the field. Scientia Horticulturae, v.108, n.4, p.408-13, 2006.

SILVA, F.A.S.; AZEVEDO, C.A.V. A new version of the assistat-statistical assistance software. In: WORLD CONGRESS ON COMPUTERS IN AGRICULTURE, 4., 2006, Orlando. Anais... Orlando: American Society of Agricultural Engineers, 2006. p.393-6.

TAIZ, L.; ZEIGER, E. Fisiologia vegetal. 3.ed. Porto Alegre: Artmed, 2004. 719p.

TURNER G.W.; GERSHENZON, J.; CROTEAU, R.B. Distribution of peltate glandular trichomes on developing leaves of peppermint. Plant Physiology, v.124, n.2, p.655$63,2000$. 